\title{
GMR
}

\section{MicroRNA-26b inhibits osteosarcoma cell migration and invasion by down-regulating PFKFB3 expression}

\author{
W.D. Zheng', F.L. Zhou' ${ }^{2}$ and N. Lin ${ }^{2}$ \\ 'Department of Orthopaedic and Trauma Surgery, Jining No.1 People's Hospital, \\ Jining, Shandong ,China \\ ${ }^{2}$ Foundation College of Jining Medical University, Jining, Shandong, China \\ Corresponding author: F.L. Zhou \\ E-mail: fenglingloveryu@163.com \\ Genet. Mol. Res. 14 (4): 16872-16879 (2015) \\ Received July 6, 2015 \\ Accepted September 28, 2015 \\ Published December 14, 2015 \\ DOI http://dx.doi.org/10.4238/2015.December.14.14
}

ABSTRACT. MicroRNAs regulate target gene expression and are involved in cell proliferation, apoptosis, differentiation, tumor invasion, and cancer stem cell regulation, among other processes. MicroRNA-26b (miR-26b) is closely related to tumor occurrence and development. In this study, we analyzed miR-26b expression in osteosarcoma tissue, its effect on Saos-2 osteosarcoma cell proliferation and invasion, and its relationship with 6-phosphofructo-2-kinase/fructose-2,6-biphosphatase 3 (PFKFB3) expression. Osteosarcoma tissue was obtained from surgical patients and normal tissue adjacent to the tumor was used as a control. Real-time polymerase chain reaction was applied to detect miR-26b expression in cancer tissue and normal tissue. A vector expressing miR-26b was constructed and transfected into Saos-2. An MTT assay, cell invasion assay, and scratch experiment were used to analyze the effect of miR$26 \mathrm{~b}$ on Saos-2 cell proliferation, invasion, and migration abilities. Western blotting analysis was performed to investigate the role of miR-26b on PFKFB3 expression. miR-26b expression in normal tissue was 7.55-fold higher than in osteosarcoma tissue $(t=10.20, P=0.006)$. Compared with 
control tissue, miR-26b significantly inhibited osteosarcoma proliferation, migration, and invasion $(P<0.05)$. Western blotting results revealed that PFKFB3 protein expression decreased in Saos-2 cells after transfection with miR-26b. miR-26b was down-regulated in osteosarcoma tissue. miR26b may inhibit osteosarcoma cell proliferation, migration, and invasion by regulating PFKFB3 protein expression. miR-26b may have a tumor suppressor role in tumor occurrence and development.

Key words: miR-26b; Oncogene; Osteosarcoma; 6-Phosphofructo-2-kinase/fructose-2,6-biphosphatase 3

\section{INTRODUCTION}

Osteosarcoma is one of the most common malignant tumors in bone and has a high degree of malignancy. Its proliferation and metastasis greatly affects patient quality of life and prognosis. The 5-year survival rate of osteosarcoma patients is only $55-68 \%$, even when patients are treated with surgery and chemotherapy (Zeng and Cullen, 2003). This is mainly because of its early metastasis, chemotherapy side effects, and impact of surgical treatment on limb function. Therefore, osteosarcoma treatment must be improved (Bartel, 2004; Esquela-Kerscher and Slack, 2006).

Currently, gene therapy is the hotspot in osteosarcoma research. The basis of osteosarcoma development and effective gene therapy targets have been widely examined. MicroRNAs (miRNAs) are non-coding small RNAs 22-28 nucleotides in length and are widely distributed in eukaryotes. miRNAs play a role in negative regulation of gene expression, causing mRNA degradation or translation inhibition (Zeng and Cullen, 2003). miRNAs may regulate the expression of related target genes to participate in cell differentiation, proliferation, apoptosis, tumor invasion and metastasis, and stem cell regulation (Hammond, 2007; Yu et al., 2010; Pizzini et al., 2013; Zhang et al., 2013).

miRNA-26b is an miRNA that plays a role as a tumor suppressor gene or oncogene in different tumors, such as lung cancer, breast cancer, bladder cancer, and liver cancer (Ji et al., 2009; Ji et al., 2010; Gao et al., 2011; Liu et al., 2011; Palumbo et al., 2013). However, few studies have investigated its role in the occurrence and development of osteosarcoma. In addition, tumor cell proliferation is associated with the anaerobic glycolysis pathway, which involves a variety of different processes and factors, such as cell growth acidic microenvironment, matrix proteins dissolution, tumor angiogenesis, and energy production for DNA synthesis. Recent studies showed that 6-phosphofructo-2-kinase/ fructose-2,6-bisphosphatase (PFKFB3) is highly expressed in a variety of tumors and can regulate and synergistically promote tumor glycolysis (Bozhko et al., 2010; Pegoraro et al., 2013).

Thus, we examined miRNA-26b and PFKFB3 expression in osteosarcoma tissue to determine the role of miRNA-26b in the occurrence and development of osteosarcoma, as well as to further validate the relationship between miRNA-26b and PFKFB3.

\section{MATERIAL AND METHODS}

\section{Patient information}

Twelve cases of resected primary osteosarcoma tissue and adjacent normal tissue were 
selected form Jining No. 1 People's Hospital between January 2007 and May 2012, and another 12 cases of normal tissue were used as controls at the same time. No subjects had received preoperative chemotherapy, radiotherapy, or endocrine therapy. The follow-up time was from the surgical treatment until April 2013. All patients received chemotherapy after surgery and no recurrence or metastasis appeared. The Saos-2 osteosarcoma cell line was obtained from the Chinese Academy of Sciences.

The study protocol was approved by the Research Ethics Committee of Jining No. 1 People's Hospital, and all patients provided informed consent before study commencement.

\section{Cell culture}

Cells were maintained in RPMI-1640 medium supplemented with $10 \%$ fetal calf serum (Gibco, Grand Island, NY, USA) in a humid atmosphere containing $5 \% \mathrm{CO}_{2}$ at $37^{\circ} \mathrm{C}$. The cells were passaged to achieve 80 to $90 \%$ confluence.

\section{microRNA extraction and reverse transcription}

The miRcute miRNA extraction and separation kit was used to extract tissue microRNAs (Tiangen Biotech, Beijing, China) according to the manufacturer instructions. MicroRNA reverse transcription was performed referred to Chen et al. (2005), and the reaction included the following: $2 \mu \mathrm{L}$ $\mathrm{ddH}_{2} \mathrm{O}, 1.7 \mu \mathrm{L} 5 \mathrm{X}$ buffer, $1.9 \mu \mathrm{L}$ microRNA stem loop primers, $1 \mu \mathrm{L}$ reverse transcriptase (Primescript RT Enzyme Mix I), and $2 \mu \mathrm{L}$ microRNA. The reverse transcription reaction conditions were as follows: $16^{\circ} \mathrm{C}$ for $30 \mathrm{~min}, 42^{\circ} \mathrm{C}$ for $30 \mathrm{~min}, 85^{\circ} \mathrm{C}$ for $8 \mathrm{~min}$, and $4^{\circ} \mathrm{C}$ for $10 \mathrm{~min}$. The products were stored at $4^{\circ} \mathrm{C}$.

\section{Real-time polymerase chain reaction (PCR)}

Real-time PCR was performed using the SYBR Premix Ex Taq (Perfect Real-Time) DRR041A kit (Takara, Shiga, Japan). The cycling conditions included an initial, single cycle of 2 min at $95^{\circ} \mathrm{C}$, followed by 35 cycles of $30 \mathrm{~s}$ at $94^{\circ} \mathrm{C}$ and $45 \mathrm{~s}$ at $60^{\circ} \mathrm{C}$. The $R Q$ Manager Analysis software was used for statistical analysis. Differences in gene expression levels between groups were compared according to the method described by Livak and Schmittgen (2001).

\section{Cell transfection}

MicroRNAs and the liposome complex was constructed by diluting miRNA with RNAfree water to a final concentration of $20 \mu \mathrm{M}$, and mixed with the Lipofectamine ${ }^{\mathrm{TM}} 2000$ (Invitrogen, Carlsbad, CA, USA) at room temperature for $20 \mathrm{~min}$ to form the miRNA-Lipofectamine ${ }^{\mathrm{TM}} 2000$ complex. A total of $3 \times 10^{5}$ cells were seeded on a 6 -well plate and maintained in $2 \mathrm{~mL}$ medium with serum but no antibiotics for $24 \mathrm{~h}$. After switching to $1 \mathrm{~mL}$ serum and antibiotic-free medium, miRNAs with liposome complexes at a final concentration of $100 \mathrm{nM}$ were added and maintained at $37^{\circ} \mathrm{C}$ and $5 \% \mathrm{CO}_{2}$ for $6 \mathrm{~h}$. The medium was changed back to normal medium for the follow-up study.

\section{Cell wound scratch assay}

Cells were seeded on a 6 -well plate for $24 \mathrm{~h}$. After the cell concentration reached $90 \%$, pipette tip was used to scratch the cells vertically. After removing the redundant cells, the cells were 
maintained in serum-free medium at $37^{\circ} \mathrm{C}$ and $5 \% \mathrm{CO}_{2}$ for $24 \mathrm{~h}$. The scratch was imaged and the width was calculated.

\section{Cell invasion assay}

For the cell invasion assay, $100 \mu \mathrm{L} 20 \mathrm{ng} / \mu \mathrm{L}$ Matrigel was added to the Transwell Chambers. After drying the chamber, $200 \mu \mathrm{L}$ cell suspension was added to the 24-well Transwell Chamber, and $500 \mu \mathrm{L}$ complete medium was added to the lower chamber. After culturing for $24 \mathrm{~h}$, the upper chamber was washed with phosphate-buffered saline 3 times and fixed with $2 \%$ phosphatebuffered saline-paraformaldehyde at room temperature for $15 \mathrm{~min}$. After removing the Matrigel and untraversed cells, the chamber was dyed with hematoxylin at room temperature for 10 min and washed with phosphate-buffered saline. The cell number was counted under the microscope. Ten random fields were for each membrane and the mean value was compared.

\section{Cell proliferation assay}

MTT was applied for cell proliferation detection. A total of 10,000 cells were seeded on a 96-well plate and maintained until the concentration reached 50-60\%. Next, $20 \mu \mathrm{L} 5 \mathrm{mg} / \mathrm{L}$ MTT was added and culture was continued for $4 \mathrm{~h}$. After removing the medium, $150 \mu \mathrm{L}$ dimethyl sulfoxide was added. The optical density of the solution was read at $490 \mathrm{~nm}$.

\section{Western blotting}

The cells were harvested and then homogenized using lysis buffer. Total protein was separated by denaturing $10 \%$ sodium dodecyl sulfate-polyacrylamide gel electrophoresis. Detection was performed using the Odyssey system (Gene Company Ltd., Chai Wan, China). The primary antibody for PFKFB3 (1:1000) was purchased from BioVision (Milpitas, CA, USA).

\section{Statistical analysis}

All statistical analyses were performed using the SPSS17.0 software (SPSS, Inc., Chicago, IL, USA). Numerical data are reported as means and standard errors ( \pm SE). Differences between means were analyzed using the Student $t$-test, q-test, or one-way analysis of variance when necessary. $\mathrm{P}<0.05$ was considered to indicate statistical significance.

\section{RESULTS}

\section{Real-time PCR}

The $\Delta \mathrm{Ct}$ of miR-26b expression in osteosarcoma tissue was $13.15 \pm 0.48$, while this value was $10.07 \pm 1.00$ in normal tissue. miR-26b expression in normal tissue was 7.55 -fold higher than that in osteosarcoma tissue $(t=10.00, P=0.006)$.

\section{Cell proliferation}

MTT results showed that after transfection for 24 and $48 \mathrm{~h}$, cell proliferation was not 
significantly different $(F=1.313,1.32 ; P=0.335,0.221)$. The cell proliferation ability showed a clear difference after transfection for 72 and $96 \mathrm{~h}(\mathrm{~F}=11.047,5.450 ; \mathrm{P}=0.003,0.024)($ Table 1$)$.

\begin{tabular}{|c|c|c|c|c|}
\hline \multirow[t]{2}{*}{ Group } & \multicolumn{4}{|c|}{$\operatorname{MTT}\left(\mathrm{OD}_{490}\right)$} \\
\hline & $24 \mathrm{~h}$ & $48 \mathrm{~h}$ & $72 \mathrm{~h}$ & $96 \mathrm{~h}$ \\
\hline 50 nM & $0.26 \pm 0.03^{\mathrm{a}}$ & $0.31 \pm 0.02^{\mathrm{a}}$ & $0.43 \pm 0.02^{\mathrm{a}}$ & $1.31 \pm 0.02^{\mathrm{a}}$ \\
\hline $100 \mathrm{nM}$ & $0.28 \pm 0.02^{\mathrm{a}}$ & $0.30 \pm 0.02^{\mathrm{a}}$ & $0.90 \pm 0.02^{b}$ & $1.20 \pm 0.02^{\mathrm{a}}$ \\
\hline Blank control & $0.26 \pm 0.03^{a}$ & $0.32 \pm 0.03^{\mathrm{a}}$ & $0.96 \pm 0.04^{b}$ & $1.61 \pm 0.03^{b}$ \\
\hline Negative control & $0.26 \pm 0.03^{a}$ & $0.32 \pm 0.03^{\mathrm{a}}$ & $0.93 \pm 0.04^{b}$ & $1.52 \pm 0.03^{b}$ \\
\hline
\end{tabular}

Different letters indicate significant differences, same letters indicate non-significant differences.

\section{Cell migration and invasion}

Compared with the control, Saos-2 cells transfected with miR-26b exhibited clearly increased migration and invasion abilities (Figures 1 and 2).
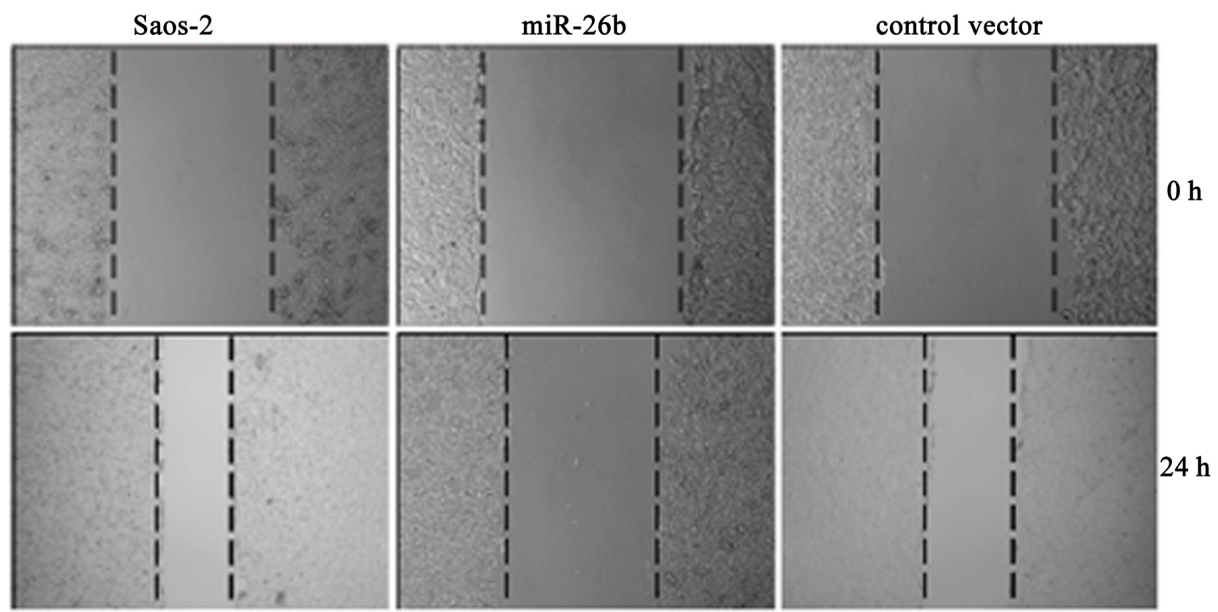

Figure 1. Effect of miR-26b on the migration of Saos-2 cells.

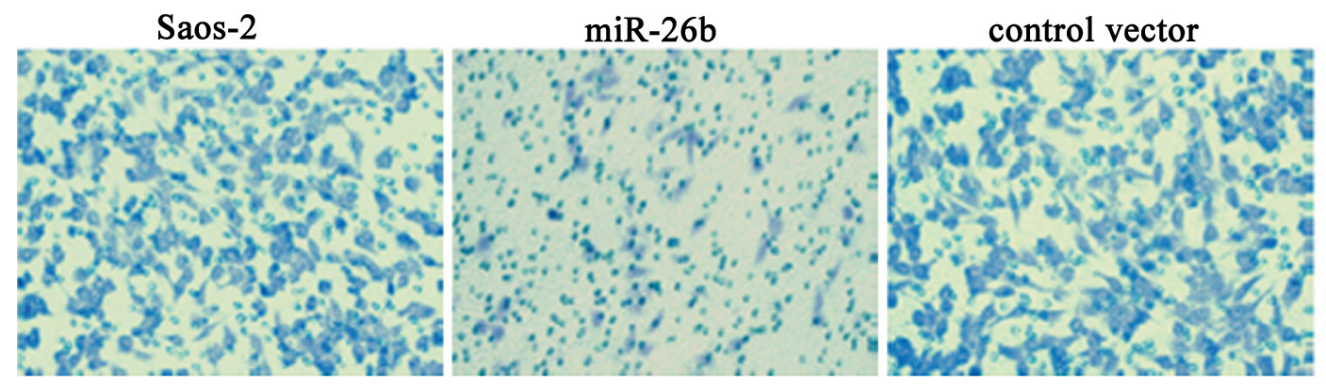

Figure 2. Effect of miR-26b on the invasion of Saos-2 cells. 


\section{Western blotting}

Western blotting results revealed that PFKFB3 protein expression decreased in Saos-2 cells after transfection with miR-26b (Figure 3).

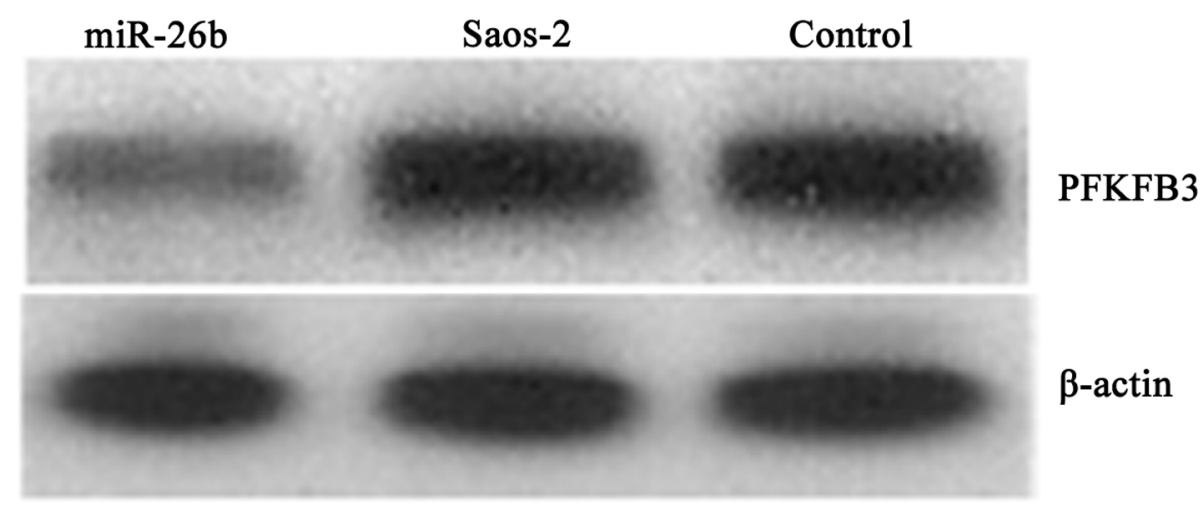

Figure 3. miR-26b inhibits PFKFB3 expression.

\section{DISCUSSION}

Numerous studies have shown that because numerous miRNAs are closely related to tumors in the genome, miRNA expression spectrum changes are closely related to tumor occurrence and development. These miRNAs can act as oncogenes or tumor suppressors (Calin et al., 2004; Hammond, 2007; Kulshreshtha et al., 2007; Zhang et al., 2013).

Recent studies revealed that miR-26b participates in tumor microenvironment regulation. miR-26b expression is significantly altered, particularly under anoxic conditions (Kulshreshtha et al., 2007). Additionally, miR-26b is down-regulated in liver cancer (Ji et al., 2009), nasopharyngeal carcinoma (Ji et al., 2010), primary lung squamous cell carcinoma (Gao et al., 2011), and glioma (Gaur et al., 2007).

In addition, studies have shown that miR-26b has multiple functions in tumor development; for example, miR-26b can affect cyclooxygenase-2 to inhibit nasopharyngeal carcinoma cell proliferation (Gao et al., 2011), while down-regulation of miR-26b can inhibit tumor invasion, clone formation, and tumor formation capacity (Liu et al., 2011). We found that miR-26b was downregulated in clinical osteosarcoma tissue, indicating that miR-26b may be a molecular marker for osteosarcoma. In osteosarcoma cells, overexpression of miR-26b may suppress osteosarcoma cell proliferation, migration, and invasion ability, and thus it may play a tumor suppressor role in osteosarcoma cells.

PFKFB3 is one of the 4 coding genes for 6-phosphofructokinase-2/fructose double phosphatase-2. It is an important regulatory enzyme for glycolysis and a strong allosteric activator of phosphofructokinase-1. This enzyme mainly exists in the human brain and placenta, and is present in a wide variety of tumor cell lines. It can decompose glycolysis 6-phosphoric acid to glycerol 3 phosphate, causing glucose to be quickly absorbed for tumor glycolysis and provides energy and materials for tumor proliferation (Seo et al., 2011). It also plays an important role in 
tumor occurrence and development as a proto-oncogene. In this study, western blotting results showed that PFKFB3 was overexpressed in osteosarcoma cells.

In addition, we found that $100 \mathrm{nM}$ miR-26b mimics can not only restrain PFKFB3 protein expression, but also mediate cell proliferation and invasion. Additionally, our results support that PFKFB3 is a target of miR-26b and miR-26b and that miR-26b participates in the process of osteosarcoma cell proliferation mediated by PFKFB3.

Traditional cancer treatment strategies mainly include endocrine therapy, surgery, radiation, and chemotherapy. All of these methods have different limitations. Following the development of molecular biology techniques, microRNA-mediated tumor molecular therapy will become an important avenue for tumor treatment because of its unique advantages. Therefore, miRNA will be used as a potential tumor target gene for genetic diagnosis, due to the changes in itsexpression in different malignant tumors. In this study, we found that miR-26b decreased in osteosarcoma cells and could control cell proliferation by mediating PFKFB3 gene expression, revealing an important suppressor role in osteosarcoma. Up-regulation of miR-26b may be used to treat osteosarcoma.

\section{Conflicts of interest}

The authors declare no conflict of interest.

\section{ACKNOWLEDGMENTS}

We thank the anonymous reviewers for reviewing this manuscript.

\section{REFERENCES}

Bartel DP (2004). MicroRNAs: genomics, biogenesis, mechanism, and function. Cell 116: 281-297.

Bozhko IV, Minchenko DO, Zinchenko TO, lavorovskiĭ OP, et al. (2010). Effect of silver nanoparticles on the expression of 6-phosphofructo-2-kinase/ fructose-2,6-bisphosphatase-2 mRNA and its alternative splice variants in different rat organs. Ukr. Biokhim. Zh. 82: 68-78.

Calin GA, Sevignani C, Dumitru CD, Hyslop T, et al. (2004). Human microRNA genes are frequently located at fragile sites and genomic regions involved in cancers. Proc. Natl. Acad. Sci. U. S. A. 101: 2999-3004.

Chen C, Ridzon DA, Broomer AJ, Zhou Z, et al. (2005). Real-time quantification of microRNAs by stem-loop RT-PCR. Nucleic Acids Res. 33: e179.

Esquela-Kerscher A and Slack FJ (2006). Oncomirs - microRNAs with a role in cancer. Nat. Rev. Cancer 6: $259-269$.

Gao W, Shen H, Liu L, Xu J, et al. (2011). MiR-21 overexpression in human primary squamous cell lung carcinoma is associated with poor patient prognosis. J. Cancer Res. Clin. Oncol. 137: 557-566.

Gaur A, Jewell DA, Liang Y, Ridzon D, et al. (2007). Characterization of microRNA expression levels and their biological correlates in human cancer cell lines. Cancer Res. 67: 2456-2468.

Hammond SM (2007). MicroRNAs as tumor suppressors. Nat. Genet. 39: 582-583.

Ji J, Shi J, Budhu A, Yu Z, et al. (2009). MicroRNA expression, survival, and response to interferon in liver cancer. N. Engl. J. Med. 361: 1437-1447.

Ji Y, He Y, Liu L and Chong X (2010). MiRNA-26b regulates the expression of cyclooxygenase-2 in desferrioxamine-treated CNE cells. FEBS Lett. 584: 961-967.

Kulshreshtha R, Ferracin M, Wojcik SE, Garzon R, et al. (2007). A microRNA signature of hypoxia. Mol. Cell Biol. 27: 18591867.

Liu XX, Li XJ, Zhang B, Liang YJ, et al. (2011). MicroRNA-26b is underexpressed in human breast cancer and induces cell apoptosis by targeting SLC7A11. FEBS Lett. 585: 1363-1367.

Livak KJ and Schmittgen TD (2001). Analysis of relative gene expression data using real-time quantitative PCR and the $2^{\triangle \Delta C t}$ method. Methods 25: 402-408.

Palumbo T, Faucz FR, Azevedo M, Xekouki P, et al. (2013). Functional screen analysis reveals miR-26b and miR-128 as central 
regulators of pituitary somatomammotrophic tumor growth through activation of the PTEN-AKT pathway. Oncogene 32 : 1651-1659.

Pegoraro C, Maczkowiak F and Monsoro-Burq AH (2013). Pfkfb (6-phosphofructo-2-kinase/fructose-2,6-bisphosphatase) isoforms display a tissue-specific and dynamic expression during Xenopus laevis development. Gene Expr. Patterns 13: 203-211.

Pizzini S, Bisognin A, Mandruzzato S, Biasiolo M, et al. (2013). Impact of microRNAs on regulatory networks and pathways in human colorectal carcinogenesis and development of metastasis. BMC Genomics 14: 589.

Seo M, Kim JD, Neau D, Sehgal I, et al. (2011). Structure-based development of small molecule PFKFB3 inhibitors: a framework for potential cancer therapeutic agents targeting the Warburg effect. PLoS One 6: e24179.

Yu F, Deng H, Yao H, Liu Q, et al. (2010). Mir-30 reduction maintains self-renewal and inhibits apoptosis in breast tumorinitiating cells. Oncogene 29: 4194-4204.

Zeng $Y$ and Cullen BR (2003). Sequence requirements for micro RNA processing and function in human cells. RNA 9: 112-123.

Zhang J, Lu Y, Yue X, Li H, et al. (2013). MiR-124 suppresses growth of human colorectal cancer by inhibiting STAT3. PLoS One 8: e70300. 